\title{
Cathepsin D Associates with Lysosomal Membranous Protein
}

\author{
Yukio NishimurA* and Masaru Himeno \\ Division of Physiological Chemistry, Faculty of Pharmaceutical Sciences, Kyushu University, Higashi-ku, Fukuoka \\ 812-82, Japan. Received May 15, 1995; accepted June 23, 1995
}

\begin{abstract}
The membrane-association of early biosynthetic form of cathepsin D has been demonstrated in hepatoma cells, and this membrane-association is not mediated by mannose 6-phosphate residues, implying that a mannose 6-phosphate receptor-independent mechanism operates in the sorting of cathepsin $D$. In this paper, to demonstrate whether cathepsin $\mathrm{D}$ is associated with the lysosomal membranes, an in vitro binding experiment was carried out employing lysosomal cathepsin D or microsomal procathepsin D isolated from rat liver. Immunoblotting analysis revealed that an intermediate form of cathepsin $D$ was associated with the lysosomal membranes; this lysosomal membrane-associated cathepsin $D$ was released from the membranes by washing with $\mathrm{Na}_{2} \mathrm{CO}_{3}(\mathrm{pH} 10.6)$ but not with solutions containing mannose 6-phosphate. This suggested that cathepsin $D$ associates with the membranes by ionic-interaction, and that the membrane-associated cathepsin $D$ resides as a peripheral membrane protein in the lysosomal membrane fraction. To confirm that the intermediate form of cathepsin D specifically interacts with the lysosomal integral membrane proteins, the lysosomal membrane fraction was treated with trypsin and the binding experiment was conducted. The result showed that the binding capacity of cathepsin $D$ to the lysosomal membranes was apparently abolished and cathepsin $D$ did not rebind to the membranes. These data suggest that the intermediate form of cathepsin $D$ is preferentially recognized by the lysosomal membranous protein which complements the mannose 6-phosphate receptor-dependent intracellular sorting mechanism.
\end{abstract}

Key words lysosome; cathepsin D; cathepsin D membrane-association; intracellular sorting; mannose 6-phosphate receptor-independent sorting

Most lysosomal enzymes so far investigated are synthesized as glycosylated preproenzymes on membranebound ribosomes of endoplasmic reticulum (ER) and follow the secretory route. ${ }^{11}$ Cathepsin D is one of the best characterized lysosomal proteinases. ${ }^{2)}$ Like other lysosomal enzymes, it is synthesized as a preproenzyme which is cleaved cotranslationally to yield the proenzyme, and the proenzyme then undergoes a multiple processing of both the polypeptide and the oligosaccharide chains before being sorted for targeting to the lysosomes. ${ }^{3)}$ The high-mannose type oligosaccharide moieties of cathepsin $\mathrm{D}$ acquire mannose 6-phosphate (M6-P) residues at the cis face of Golgi complex and are recognized by a specific receptor (M6-P receptor; MPR) at the trans face of Golgi complex, which results in their delivery to the lysosomes. ${ }^{1)}$ In contrast to this transport mechanism, the membraneassociation of an early biosynthetic form of cathepsin D has been demonstrated in HepG2 cells, ${ }^{4,5)}$ and this membrane-association is not mediated by M6-P residues, suggesting that an MPR-independent mechanism operates in the sorting of cathepsin D. Similarly, procathepsin D was found to be membrane-bound in the macrophage endosomes, ${ }^{6)}$ and procathepsin $\mathrm{L}$ was membraneassociated in the microsomal vesicles at $\mathrm{pH} 5$ as demonstrated by in vitro binding experiments. ${ }^{7,8)}$ These results suggested that the membrane-association between the precursor of cathepsin polypeptide and the microsomal vesicles is essential for correct sorting to the lysosomes. However, the physiological function of these membraneinteraction has not yet been clarified. Also, the targeting of lysosomal-like vacuolar proteins in Saccharomyces cerevisiae does not seem to be dependent on the M6-P residues of their core oligosaccharides. ${ }^{9,10)}$ The mutational analysis of vacuolar protein determinants has recently demonstrated that the short peptide portion consisting of four amino acids (QPRL) of the precursor carboxy-

* To whom correspondence should be addressed. peptidase $\mathrm{Y}$ is the determinant to be recognized in the intracellular sorting pathway. ${ }^{11)}$ We have recently succeeded in expressing mouse cathepsin L cDNA and rat cathepsin D cDNA in Saccharomyces cerevisiae. We demonstrated by cell fractionation experiments that the precursor enzyme is transported to the yeast vacuoles. ${ }^{12,13)}$ The cathepsin L polypeptide was found to be tightly associated with the vacuolar membranes, implying that cathepsin polypeptide is recognized by the sorting machinery of yeast vacuolar proteins and that it is selectively targeted to the yeast vacuoles. If, indeed, precursor cathepsin $\mathrm{D}$ is translocated to the lysosomes by these proposed MPR-independent sorting mechanisms, it is assumed that the intracellular membranes of the transport vesicles such as the endosomes or lysosomes could have an appreciable capacity to bind cathepsin D polypeptide.

In this paper, to determine whether cathepsin D is associated with the lysosomal membranes, an in vitro binding experiment was carried out employing the lysosomal cathepsin D fraction or the microsomal procathepsin $\mathrm{D}$ fraction. We here demonstrate that the intermediate form of cathepsin $\mathrm{D}$ is bound to the lysosomal membranes, and that cathepsin D is associated with the membranes by ionic-interaction. Thus, the membraneassociated cathepsin D apparently resides as a peripheral membrane protein in the lysosomal membrane fraction.

\section{MATERIALS AND METHODS}

Animals Male Wistar rats weighing 200-250g were used.

Materials Triton WR-1339 was purchased from Rohm and Haas (Philadelphia, Pa, U.S.A.); E-64, pepstatin A, leupeptin were purchased from the Peptide Research Foundation (Osaka, Japan); phenylmethanesulfonyl fluo-

(C) 1995 Pharmaceutical Society of Japan 
ride was obtained from Boehringer Mannheim $\mathrm{GmbH}$ (Germany). Con A-Sepharose 4B and the molecular weight mass markers for immunoblotting were from Pharmacia LKB Biotechnology Inc. (U.K.) and all other chemicals were guaranteed reagent grade obtained from Katayama Chemical Industries Co., Ltd. (Osaka, Japan).

Antibody Cathepsin D was isolated to homogeneity as described. ${ }^{14)}$ Antiserum against rat liver lysosomal cathepsin D was prepared as described ${ }^{15)}$ and antibody was prepared by immunoaffinity chromatography using antigen-Sepharose 4B.

Preparation of Lysosomal Membranes The preparation of the lysosomal membranes was carried out as described previously. ${ }^{16)}$ The male Wistar rats $(200-250 \mathrm{~g})$ were fasted overnight, killed by decapitation and the livers were removed. The $25 \%$ homogenates were prepared in $0.25 \mathrm{M}$ sucrose containing $0.2 \mathrm{M} \mathrm{KCl}$ using a Waring blender (Nihon Seiki, Tokyo, Japan) at top speed for $30 \mathrm{~s}$. The homogenate was centrifuged at $650 \times \boldsymbol{g}$ for $5 \mathrm{~min}$. The pellet was resuspended in the same volume of $0.25 \mathrm{M}$ sucrose containing $0.2 \mathrm{M} \mathrm{NaCl}$ and was recentrifuged. The supernatants were combined and centrifuged at $11000 \times \boldsymbol{g}$ for $30 \mathrm{~min}$. The mitochondria-lysosomal fraction in the pellet form thus obtained was suspended in a hypotonic solution and then centrifuged at $11000 \times \boldsymbol{g}$ for $20 \mathrm{~min}$. The supernatant was decanted carefully and the pellet was suspended in the hypotonic buffer and centrifuged again at $11000 \times \boldsymbol{g}$ for $20 \mathrm{~min}$. The resultant supernatants were combined and designated as a crude lysosomal membrane fraction. This crude fraction was added with $\mathrm{CaCl}_{2}$ to give a final concentration of $10 \mathrm{~mm}$ and was then subjected to successive differential centrifugation at $1500 \times \boldsymbol{g}$ for $10 \mathrm{~min}$, at $5000 \times \boldsymbol{g}$ for $10 \mathrm{~min}$, at $10000 \times \boldsymbol{g}$ for $30 \mathrm{~min}, 50000 \times \boldsymbol{g}$ for $30 \mathrm{~min}$, and $105000 \times \boldsymbol{g}$ for $30 \mathrm{~min}$. Purified lysosomal membranes were obtained after the centrifugation at $50000 \times \mathbf{g}$ as a pellet which was suspended with $0.25 \mathrm{M}$ sucrose (pH 7.0). The high-specific activity of acid phosphatase, a marker enzyme for the lysosomes, was found in the purified lysosomal membranes with $7000 \mathrm{nmol} / \mathrm{mg}$ protein which was approximately 100 -fold of the total homogenate.

Preparation of the Tritosomes Rats were injected intraperitoneally with Triton WR 1339 at the dosage of $85 \mathrm{mg} / 100 \mathrm{~g}$ body weight $84 \mathrm{~h}$ before sacrifice. Tritosomes were prepared from the livers $(40 \mathrm{~g})$ as described. ${ }^{17,18)}$ To subfractionate them into membranes and soluble contents, the prepared tritosomes were subjected to osmotic shock treatment by resuspending the samples in hypotonic solution $(0.025 \mathrm{M}$ sucrose), and the suspension was centrifuged at $105000 \times \boldsymbol{g}$ for $60 \mathrm{~min}$ yielding the pellet and the supernatant (tritosomal contents). The resulting pellets were resuspended in $1 \mathrm{M} \mathrm{NaCl}$ solution, and centrifuged again at $105000 \times g$ for $60 \mathrm{~min}$ to give the supernatant ( $1 \mathrm{M} \mathrm{NaCl}$ washings) and the pellet (tritosomal membrane). The resultant tritosomal membrane was suspended in $10 \mathrm{~mm}$ Tris- $\mathrm{HCl}$ buffer, $\mathrm{pH} \mathrm{7.4,} \mathrm{containing}$ $10 \mathrm{~mm}$ M6-P, $1 \mathrm{~mm}$ EDTA, $1 \mathrm{~mm}$ EGTA.

Lysis of the Lysosomal Membranes The purified lysosomal membranes were subjected to osmotic shock treatment by resuspending the samples in hypotonic solution $(0.025 \mathrm{M}$ sucrose $)$ and the suspension was centrifuged at $105000 \times \boldsymbol{g}$ for $60 \mathrm{~min}$. The resultant pellets were resuspended in $1 \mathrm{M} \mathrm{NaCl}$ solution, and centrifuged again at $105000 \times \boldsymbol{g}$ for $60 \mathrm{~min}$. The resultant lysosomal membrane as a pellet was suspended in $10 \mathrm{~mm}$ Tris $-\mathrm{HCl}$ buffer, $\mathrm{pH}$ 7.4, containing $10 \mathrm{~mm}$ M6-P, $1 \mathrm{~mm}$ EDTA, $1 \mathrm{~mm}$ EGTA and homogenized and centrifuged at $105000 \times g$ for $60 \mathrm{~min}$. Pellets thus obtained were further resuspended with $0.1 \mathrm{M} \mathrm{Na}_{2} \mathrm{CO}_{3}$ (pH 10.6) containing $10 \mathrm{~mm} \mathrm{M} 6-\mathrm{P}$, left on ice for $30 \mathrm{~min}$, and subjected to centrifugation at $105000 \times \mathrm{g}$ for $60 \mathrm{~min}$ at $4^{\circ} \mathrm{C}$. The resultant pellet as the stripped lysosomal membranes was suspended in the buffer of $\mathrm{pH} 4.5$ or 7.4 containing $10 \mathrm{~mm}$ M6-P, $1 \mathrm{~mm}$ EDTA, and $1 \mathrm{~mm}$ EGTA and used in the membrane binding experiments. The supernatant containing the intermediate form of cathepsin D was concentrated, dialyzed against the buffer of $\mathrm{pH} 4.5$ or $\mathrm{pH} 7.4$ and used in the membrane binding experiments as a source of cathepsin D.

The purified lysosomal membranes as described above were suspended in $10 \mathrm{~mm}$ Tris- $\mathrm{HCl}$ buffer $(\mathrm{pH} \mathrm{7.4)}$ and then incubated with trypsin $(100 \mu \mathrm{g} / \mathrm{ml})$ for $60 \mathrm{~min}$ at $4{ }^{\circ} \mathrm{C}$. Proteolysis was terminated by adding the trypsin inhibitor $(500 \mu \mathrm{g} / \mathrm{ml})$ and centrifugation followed at $105000 \times \boldsymbol{g}$ for $60 \mathrm{~min}$ at $4{ }^{\circ} \mathrm{C}$. The lysosomal membranes thus obtained were used in the membrane binding experiments.

Membrane Binding Experiments As stated, stripped lysosomal membranes and trypsin-treated lysosomal membranes prepared from rat liver were used in the membrane binding experiments. Twenty $\mu \mathrm{l}(50 \mu \mathrm{g})$ of stripped lysosomal membranes was mixed with the intermediate cathepsin D fraction obtained from the lysosomal membranes washed with sodium carbonate $(\mathrm{pH}$ 10.6) buffer or the procathepsin $D$ fraction prepared from the microsomal content fraction in $100 \mu 1$ of the buffer at $\mathrm{pH} 4.5$ or $\mathrm{pH}$ 7.4. The buffer contained $10 \mathrm{~mm}$ Tris- $\mathrm{HCl}$ or $10 \mathrm{~mm}$ sodium acetate, $10 \mathrm{~mm}$ M6-P, $1 \mathrm{~mm}$ EDTA, $1 \mathrm{~mm}$ EGTA and proteinase inhibitors (1 mM phenylmethanesulfonyl fluoride, $1 \mu \mathrm{M}$ pepstatin, $10 \mu \mathrm{M} \mathrm{E}-64,100 \mu \mathrm{M}$ leupeptin). The combined samples were incubated at $4{ }^{\circ} \mathrm{C}$ for $120 \mathrm{~min}$ and thereafter the lysosomal membranes were separated by centrifugation at $105000 \times g$ for $60 \mathrm{~min}$. The lysosomal membranes as a pellet were washed once with the binding buffer and centrifuged again. The resultant pellet suspended with $10 \mathrm{~mm}$ Tris- $\mathrm{HCl}$ buffer, $\mathrm{pH} 7.4$ or the supernatant was subjected to sodium dodecyl sulfatepolyacrylamide gel electrophoresis (SDS-PAGE) and immunoblotting analysis with anti-cathepsin D IgG.

Preparation of Microsomal Procathepsin D The microsomal procathepsin D was prepared as described previously. ${ }^{14)}$ Rat liver microsomal fraction was solubilized with $0.26 \%$ sodium deoxycholate. After the extract was precipitated with ammonium sulfate, it was applied to Con A-Sepharose equilibrated with $50 \mathrm{~mm}$ Hepes buffer, $\mathrm{pH}$ 7.5. The microsomal fraction adsorbed to the Con A-Sepharose column was eluted with $0.5 \mathrm{M}$ methyl $\alpha$-mannoside. The fraction eluted from the Con A column was immediately applied to pepstatin-Sepharose equilibrated with $1 \mathrm{M} \mathrm{NaCl} / 0.5 \mathrm{M}$ sodium acetate buffer $(\mathrm{pH}$ 5.0 ) and the flow-through fractions from the column were pooled, concentrated and used as the microsomal procathepsin D fraction. When this fraction was analyzed 
by SDS-PAGE and immunoblotting, procathepsin D was clearly revealed to be a single band with a molecular weight of $46 \mathrm{kDa}$.

Enzyme Assays Cathepsin D activity was determined by a modification of the method of Anson ${ }^{19)}$ as described previously. ${ }^{14)}$ The enzyme activity was determined with reference to a tyrosine standard curve. Units were expressed as micrograms of tyrosine solubilized per minute. ${ }^{14)}$ The activity of acid phosphatase was assayed as described by Shibko and Tappel ${ }^{201}$ using $p$-nitrophenylphosphate as substrate. One unit hydrolyzes $1 \mathrm{nmol}$ of the substrate for $1 \mathrm{~min}$ at $37^{\circ} \mathrm{C}$.

Protein Determination Proteins were determined by the method of Lowry et al. ${ }^{21)}$ with bovine serum albumin as standard.

Immunoblotting SDS-PAGE was carried out using $10 \%$ polyacrylamide gels containing $0.1 \%$ SDS. The gel was blotted onto nitrocellulose filter as described, ${ }^{14)}$ and the filter was incubated with phosphate-buffered saline (PBS) containing $0.5 \%$ skim milk powder and $0.05 \%$ Tween 20 , then treated with appropriate antibody at room temperature for $1 \mathrm{~h}$. The filter was washed with PBS and then treated with horseradish peroxidase-conjugated goat anti-rabbit antibody in PBS for $2 \mathrm{~h}$. After washing 5 times for $5 \mathrm{~min}$ each, the immunoreactive bands were visualized with a Renaissance Western blotting analysis system (DuPont NEN, Boston, MA, U.S.A.).

\section{RESULTS}

Cathepsin D Is Partly Bound to the Isolated Lysosomal Membranes It was demonstrated earlier that the biosynthetic intermediate form of cathepsin D is associated with the membranes of the intracellular compartments before being delivered to the lysosomes in HepG2 cells, and that this membrane-associated form which is independent of the presence of $\mathrm{N}$-glycosylation becomes a soluble form after proteolytic processing. ${ }^{4,5)}$ Furthermore, cathepsins $\mathrm{D}$ and $\mathrm{L}$ were found to be associated with the microsomal membranes during biosynthesis as demonstrated by the in vitro binding experiments. ${ }^{6-8)}$ These results raise the possibility that the polypeptide backbone of cathepsin $\mathrm{D}$ is recognized by the intracellular membranes which participate in the sorting of lysosomal cathepsin D. Therefore, we sought to determine whether the lysosomal membranes have the capacity to bind cathepsin $\mathrm{D}$ in vitro.

When the isolated lysosomal membranes were subjected to SDS-PAGE and immunoblotting with anti-cathepsin D IgG, cathepsin D was found to be bound to these membranes (Fig.1, lane 3). The molecular form of cathepsin D was revealed to have relatively slower mobility than that of the mature form of lysosomal enzyme, indicating that the membrane bound form of cathepsin D is possibly the processed intermediate form. As shown in Table 1, the distribution of enzymatically active cathepsin $\mathrm{D}$ in the subfractionated tritosomes indicated that the amounts of membrane-associated cathepsin $\mathrm{D}$ were at a significantly lower level than those of the active mature enzyme. Since the membrane-bound form cathepsin D was the intermediate form of the enzyme, it is possible
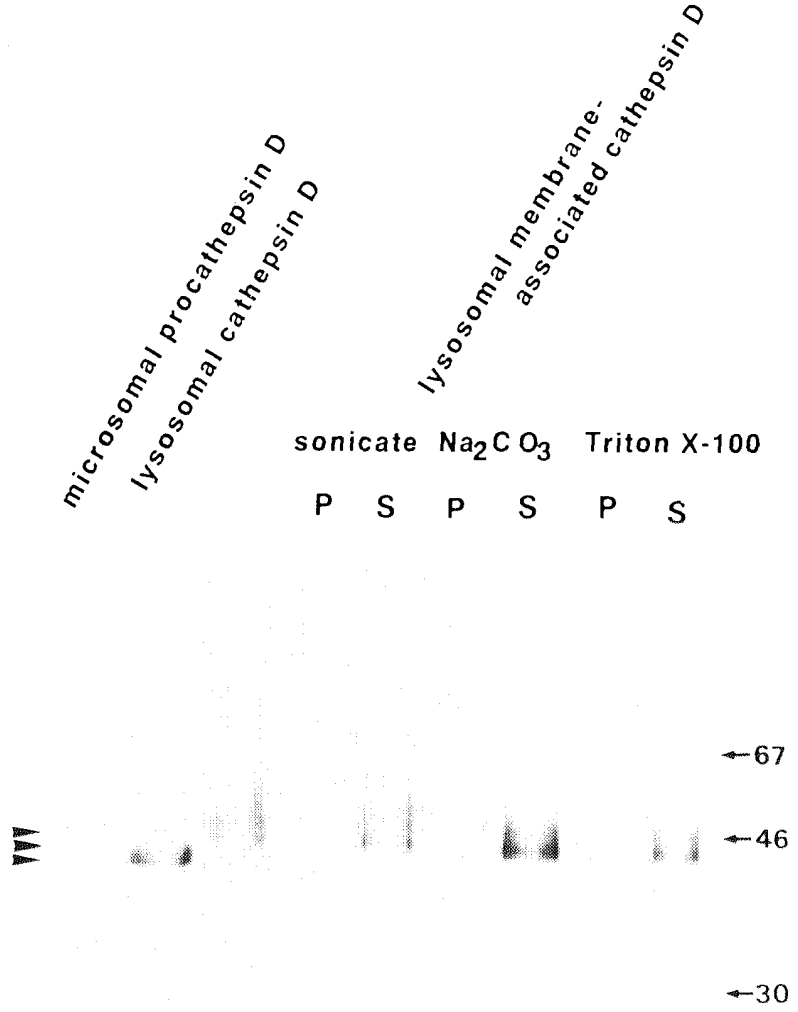

$\begin{array}{lllllllll}1 & 2 & 3 & 4 & 5 & 6 & 7 & 8 & 9\end{array}$

Fig. 1. Cathepsin D Bound to the Lysosomal Membranes Is Not Integral to the Membranes

Rat liver lysosomal membranes were isolated by the simplified procedures described previously. ${ }^{16)}$ The isolated membranes were treated with osmotic shock by suspending the samples in hypotonic solution $(0.025 \mathrm{M}$ sucrose solution, $\mathrm{pH} 7.4)$ to remove the soluble proteins trapped within the lysosomal lumen. Peripheral proteins associated with the lysosomal membranes were then carefully removed by treatment with the osmotic solution containing $1 \mathrm{M} \mathrm{NaCl}$. The prepared lysosomal membranes were subjected to $10 \%$ SDS PAGE followed by immunoblotting analysis (lane 3). They were then treated with sonication (lanes $4-5$ ), $0.1 \mathrm{M} \mathrm{Na}{ }_{2} \mathrm{CO}_{3}$ $(\mathrm{pH} 10.6)$ at $0 \mathrm{C}$ for $30 \mathrm{~min}$ (lanes $6-7)$, or $1 \%$ Triton X-100 (pH 7.4) (lanes $8-9)$, respectively, and the resultant solution was separated by centrifugation at $105000 \times g$ for 60 min at 4 C to separate the supernatant $(\mathrm{S})$ and the pellet (P). Immunoblotting was done with specific $\operatorname{IgG}$ against rat cathepsin $\mathrm{D}$ after SDS-PAGE. The arrowheads at left show the position of the 46-kDa procathepsin $\mathrm{D}$, the $45-\mathrm{kDa}$ intermediate form of cathepsin $\mathrm{D}$, and the $44-\mathrm{kDa}$ mature cathepsin $\mathrm{D}$, respectively. The numbers to the right indicate the masses of molecular weight standards in kilodaltons.

to speculate that this processed enzyme expresses a considerably lower level of enzymatic activity as compared with that of the mature enzyme. We assume that in the lysosomal fraction, most of the cathepsin D polypeptide exists as the processed mature form which is enzymatically active; therefore, the membrane-bound intermediate form is presumably an inactive enzyme.

To investigate the releasing pattern of the intermediate form of cathepsin D from the membrane, the isolated lysosomal membranes were treated with sonication (Fig. 1, lanes 4, 5), $0.1 \mathrm{M} \mathrm{Na}_{2} \mathrm{CO}_{3}\left(\mathrm{pH} \mathrm{10.6)}\right.$ at $0{ }^{\circ} \mathrm{C}$ for $30 \mathrm{~min}$ (lanes 6, 7), and 1\% Triton X-100 (pH 7.4) (lanes 8, 9), respectively, and the resultant solution was subjected to centrifugation at $105000 \times \boldsymbol{g}$ for $60 \mathrm{~min}$ at $4{ }^{\circ} \mathrm{C}$ to separate the supernatant and the pellet. Immunoblotting was done with specific IgG against rat cathepsin D after SDS- 
PAGE. Immunoblotting analysis showed that the membrane-associated cathepsin D is recovered in the supernatant after treatments by sonication or sodium carbonate, suggesting that cathepsin $\mathrm{D}$ is bound to the lysosomal membranes, similar to the case of peripheral membrane proteins. Since the prepared lysosomal membranes were washed with the buffer containing $10 \mathrm{~mm}$ M6-P, the membrane-association of cathepsin D seems to be mediated by an MPR-independent mechanism.

Lysosomal Membranes Revealed as Inverted Vesicles Following Osmotic Shock Treatment It is known that a simple injection of Triton WR1339 alters the density of rat liver lysosomes which permits separation of the lysosomes from mitochondria and peroxisomes ${ }^{17,18)}$; the membranes of tritosomes were studied in detail with respect to their enzyme profiles and chemical compositions including glycoproteins. ${ }^{17,18)}$ We prepared both tritosome membranes and the normal lysosomal membranes and used them in the following experiments to determine the interaction between cathepsin $\mathrm{D}$ and the latter membranes.

Both types of prepared membranes were subjected to osmotic shock treatments with $0.025 \mathrm{M}$ sucrose followed by washing with $1 \mathrm{M} \mathrm{NaCl}$, and then the suspensions were centrifuged at $105000 \times g$ for $60 \mathrm{~min}$ at $4^{\circ} \mathrm{C}$ to separate the supernatant and precipitate. The resultant precipitates were suspended in $10 \mathrm{~mm}$ Tris- $\mathrm{HCl}$ buffer, $\mathrm{pH} 7.4$ containing proteinase inhibitors $(1 \mu \mathrm{M}$ pepstatin and $10 \mu \mathrm{M}$ E-64). The combined samples were incubated at $4^{\circ} \mathrm{C}$. The lysosomal membranes or the intact tritosomes thus obtained were digested with different concentrations of trypsin for $60 \mathrm{~min}$ at $4{ }^{\circ} \mathrm{C}$, and then the membranes were recovered by centrifugation at $105000 \times g$ for $60 \mathrm{~min}$ at $4{ }^{\circ} \mathrm{C}$. The membranes were analyzed by SDS-PAGE and immunoblotting. As shown in Fig. 2, the cathepsin D polypeptide in the lysosomal membranes (panel A, lanes $1-4$ ) and in the tritosomal membranes (panel B, lanes 4-6) was found to be sensitive to the trypsin digestion and the cathepsin D band completely disappeared on the immunoblot, although the cathepsin $\mathrm{D}$ polypeptide in the intact tritosomes remained unchanged (panel B, lanes $1-3$ ). This suggested that disruption of the lysosomal or tritosomal membranes by the hypo-osmotic treatment caused the membranes to become inside-out vesicles, and thereby cathepsin $\mathrm{D}$ to be exposed on the outer surfaces of the lysosomal membranes after the osmotic-shock treatment. However, we cannot rule out the possibility that part of the disrupted lysosomal membranes are composed of fragmented membranes, therefore, it is assumed that the membranes thus prepared by hypoosmotic treatment would be a mixture of inside-out vesicles, right side-out vesicles, and fragmented membranes.

Cathepsin D Derived from the Lysosomal Membrane Fraction Rebinds to the Inverted Lysosomal Membranes The prepared lysosomal membranes were stripped of cathepsin $\mathrm{D}$ by washing with $\mathrm{Na}_{2} \mathrm{CO}_{3}$ (pH 10.6) containing $10 \mathrm{~mm}$ M6-P, $1 \mathrm{~mm}$ EDTA, and $1 \mathrm{~mm}$ EGTA. The stripped lysosomal membranes were centrifuged and the resultant pellet was suspended with $10 \mathrm{~mm}$ Tris- $\mathrm{HCl}$ buffer ( $\mathrm{pH}$ 7.4) containing $10 \mathrm{~mm}$ M6-P. The supernatant (membrane-wash) containing the intermediate form of
(A)

\section{Lysosomal membrane}

$\operatorname{Trypsin}(\mu \mathrm{g} / \mathrm{ml}) \quad 0 \quad 10 \quad 30100$

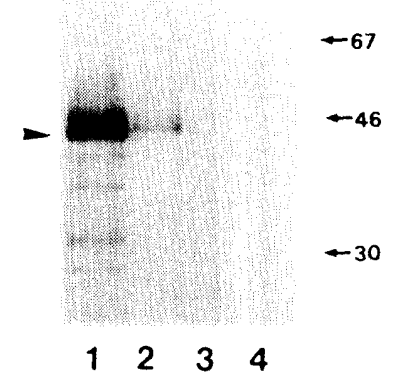

(B) Tritosomal membrane

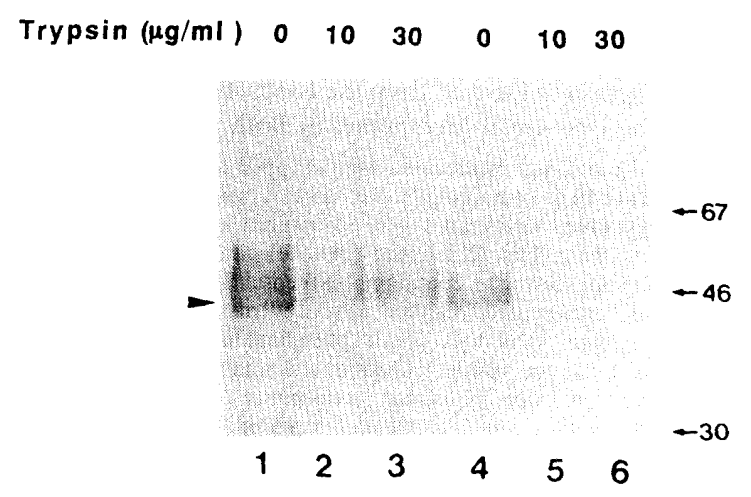

Fig. 2. Cathepsin D Associated with the Lysosomal Membranes Faces Outside after the Osmotic Treatment

The prepared lysosomal membranes or tritosomal membranes were subjected to osmotic shock treatment followed by washing with $1 \mathrm{M} \mathrm{NaCl}$, and then the suspensions were centrifuged at $105000 \times g$ for $60 \mathrm{~min}$ to separate the supernatant and precipitate. The resultant precipitates were suspended with $10 \mathrm{~mm}$ Tris- $\mathrm{HCl}$ buffer, $\mathrm{pH} 7.4$ containing proteinase inhibitors ( $1 \mu \mathrm{M}$ pepstatin and $10 \mu \mathrm{M}$ E-64) Each lysosomal membrane (panel A, lanes $1-4$ ), intact tritosome (panel B, lanes $1-3$ ), and tritosomal membrane (panel B, lanes $4-6$ ) was digested with a different concentration of trypsin at $4^{\circ} \mathrm{C}$ for $60 \mathrm{~min}$, and then the membranes were recovered by centrifugation at $105000 \times \mathrm{g}$ for $60 \mathrm{~min}$ at $4^{\circ} \mathrm{C}$ after the addition of $500 \mu \mathrm{g} / \mathrm{ml}$ of trypsin inhibitor. The membranes were analyzed by SDS-PAGE and immunoblotting with specific IgG. Arrowhead indicates the position of membraneassociated form of cathepsin $D$. Numbers to the right indicate the masses of molecular weight standards in kilodaltons.

cathespin $D$ was concentrated, dialyzed against $10 \mathrm{~mm}$ Tris- $\mathrm{HCl}$ buffer ( $\mathrm{pH}$ 7.4) containing proteinase inhibitors $(1 \mathrm{mM}$ phenylmethanesulfonyl fluoride, $1 \mu \mathrm{M}$ pepstatin, $10 \mu \mathrm{M} \mathrm{E}-64$, and $100 \mu \mathrm{M}$ leupeptin) and was used in the following rebinding experiments for cathepsin $D$. The stripped lysosomal membranes were incubated with the membrane-wash fraction at $4{ }^{\circ} \mathrm{C}$ for $90 \mathrm{~min}$ at a pH of 4.5 or 7.4. The membrane fractions were collected by centrifugation at $105000 \times \mathrm{g}$ for $60 \mathrm{~min}$ at $4^{\circ} \mathrm{C}$ after the incubation, and the resultant supernatant and pellet were analyzed by SDS-PAGE and immunoblotting. The intermediate form of cathepsin D was shown to rebind to the lysosomal membranes at acidic $\mathrm{pH}$ and at neutral $\mathrm{pH}$, and this rebinding was not mediated by M6-P or nonspecific interaction since the binding buffer included $10 \mathrm{~mm}$ M6-P (Fig. 3).

Procathepsin D Derived from the Microsomal Content Fraction Rebinds the Lysosomal Membranes at Acidic 


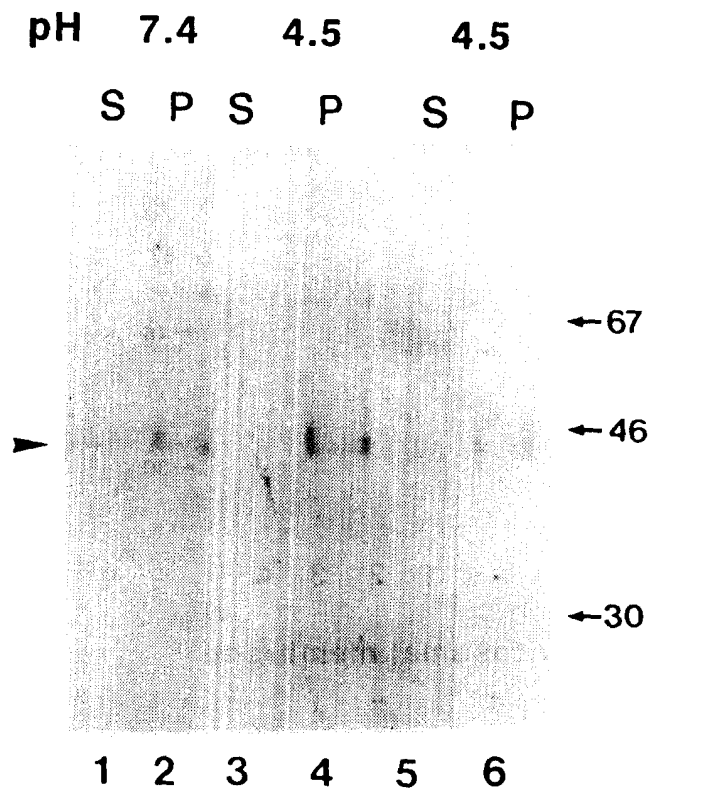

Fig. 3. Cathepsin D Derived from the Lysosomal Membrane Fraction Rebinds to the Lysosomal Membranes at Both Neutral and Acidic pH

The prepared lysosomal membranes were stripped of cathepsin $\mathrm{D}$ by washing with $\mathrm{Na}_{2} \mathrm{CO}_{3}$ (pH 10.6) containing $10 \mathrm{~mm}$ M6-P, $1 \mathrm{~mm}$ EDTA, and $1 \mathrm{~mm}$ EGTA The stripped lysosomal membranes were centrifuged and the resultant pellet was suspended with $10 \mathrm{~mm}$ Tris $\mathrm{HCl}$ buffer $(\mathrm{pH} \mathrm{7.4)}$ containing $10 \mathrm{~mm}$ M6-P. The supernatant (membrane-wash) containing cathepsin D bound to the lysosomal membranes was concentrated, dialyzed against $10 \mathrm{~mm}$ Tris- $\mathrm{HCl}$ buffer (pH 7.4) containing proteinase inhibitors ( $1 \mathrm{mM}$ phenylmethanesulfonyl fluoride, $1 \mu \mathrm{M}$ pepstatin, $10 \mu \mathrm{M} \mathrm{E}-64$, and $100 \mu \mathrm{m}$ leupeptin) and was used in subsequent binding experiments. The stripped lysosomal membranes were incubated with the membrane-wash fraction at $4^{\circ} \mathrm{C}$ for $90 \mathrm{~min}$ at $\mathrm{pH}$ of 4.5 in the presence (lanes 3 , 4) or absence (lanes 5,6) of M6-P and at pH 7.4 (lanes 1,2) in the presence of M6-P, respectively. The membrane fraction was collected by centrifugation at $105000 \times g$ for $60 \mathrm{~min}$ at $4{ }^{\circ} \mathrm{C}$, and the resultant supernatant (S) (lanes $1,3,5$ ) and pellet (P) (lanes 2, 4, 6) was analyzed by SDS-PAGE and immunoblotting. Arrowhead at the left indicates the intermediate form of cathepsin D. Numbers to the right indicate the masses of molecular weight standards in kilodaltons.

pH The stripped lysosomal membranes were prepared by washing with $\mathrm{Na}_{2} \mathrm{CO}_{3}(\mathrm{pH}$ 10.6) as described in Materials and Methods and used in the following rebinding experiments. The prepared microsomal procathepsin $\mathrm{D}$ fraction was incubated with the stripped lysosomal membranes at $4{ }^{\circ} \mathrm{C}$ for $90 \mathrm{~min}$ at a pH of 4.5 or 7.4 , the membrane fraction was collected by centrifugation at $105000 \times \mathrm{g}$ for $60 \mathrm{~min}$ at $4{ }^{\circ} \mathrm{C}$, and the resultant supernatant and pellet were analyzed by SDS-PAGE and immunoblotting (Fig. 4). Microsomal procathepsin D rebound efficiently to the lysosomal membranes at acidic $\mathrm{pH}$ of 4.5 but not at neutral $\mathrm{pH}$ of 7.4. It was reported that procathepsin $\mathrm{D}$ preferentially binds to the microsomal membranes at $\mathrm{pH} 5.0$ but not at $\mathrm{pH} 6-8 .^{7,8)}$ In this context, our results seem to coincide with the previous findings.

The Binding Capacity of Cathepsin D to Lysosomal Membranes is Reduced by Trypsin Treatment It is assumed that the intermediate form of cathepsin D has preferential binding affinity to the membranous proteins integral to the lysosomal membranes. If so, treatment of the isolated lysosomal membranes with a proteinase will cause reduction in the amount of cathepsin $\mathrm{D}$ form binding to the lysosomal membranes. We next examined the interaction between the intermediate form of cathespin $D$ and the proteinase-treated lysosomal membranes. The lysosomal membrane fraction washed with $1 \mathrm{M} \mathrm{NaCl}$ was

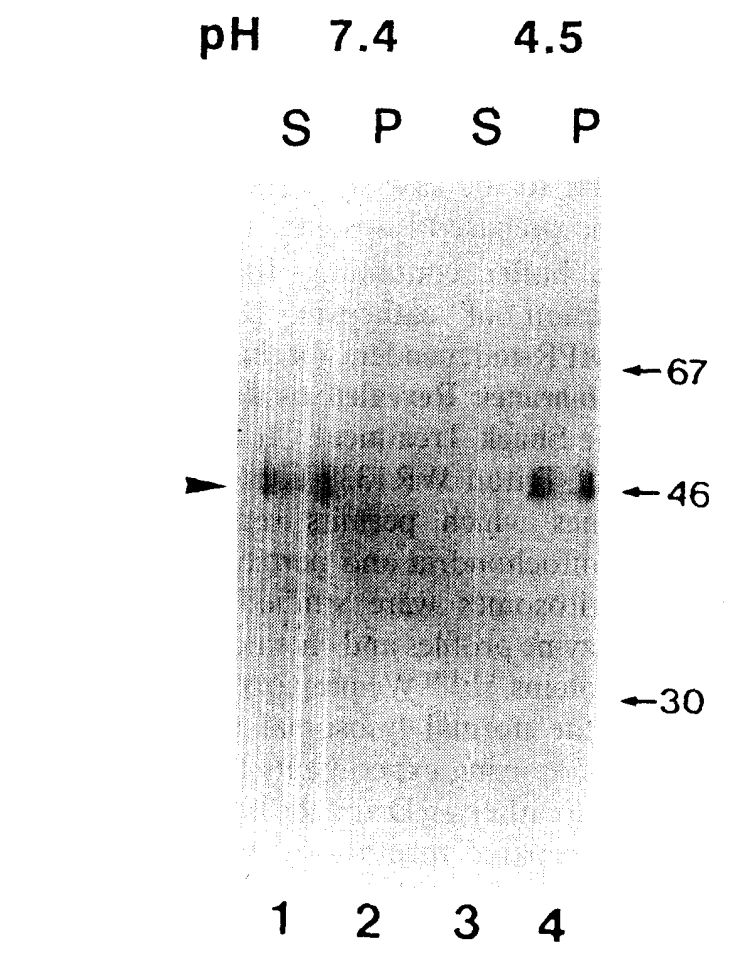

Fig. 4. Microsomal Procathepsin D Binds to the Lysosomal Membranes at Acidic pH

The stripped lysosomal membranes were prepared by washing with $\mathrm{Na}_{2} \mathrm{CO}_{3}$ ( $\mathrm{pH}$ 10.6) as described in "Materials and Methods" and used in subsequent rebinding experiments. After the microsomal procathepsin D fraction eluted from Con A-Sepharose column with $0.5 \mathrm{M} \alpha$-methyl mannoside was incubated with the stripped lysosomal membranes at $4^{\circ} \mathrm{C}$ for $90 \mathrm{~min}$ at different $\mathrm{pH}$ of 4.5 (lanes 3 , 4) or 7.4 (lanes 1,2) in the presence of M6-P, the membrane fraction was collected by centrifugation at $105000 \times g$ for $60 \mathrm{~min}$ at $4{ }^{\circ} \mathrm{C}$, and the resultant supernatan (S) (lane 1,3) and pellet (P) (lanes 2,4) were analyzed by SDS-PAGE and immunoblotting with specific IgG. Arrowhead at the left shows the intermediate form of cathepsin D. Numbers to the right indicate the masses of molecular weight standards in kilodaltons.

suspended in $10 \mathrm{~mm}$ Tris- $\mathrm{HCl}$ buffer $(\mathrm{pH} 7.4)$ and then incubated with the serine proteinase, trypsin $(100 \mu \mathrm{g} / \mathrm{ml})$, for $60 \mathrm{~min}$. Proteolysis was inhibited by adding the tryp$\sin$ inhibitor $(500 \mu \mathrm{g} / \mathrm{ml})$ and centrifugation followed at $105000 \times \mathrm{g}$ for $60 \mathrm{~min}$ at $4{ }^{\circ} \mathrm{C}$. The trypsin-treated lysosomal membranes were washed once with the membrane-binding buffer. The lysosomal membranes thus obtained were incubated with the lysosomal membranewash fraction at $\mathrm{pH} 4.5$ or 7.4 , and then the membrane and the soluble fractions were separated by centrifugation at $105000 \times g$ for $60 \mathrm{~min}$ at $4{ }^{\circ} \mathrm{C}$, followed by analysis by SDS-PAGE and immunoblotting with anti-cathepsin D IgG (Fig. 5). The result showed that the binding capacity of cathepsin D to the lysosomal membranes is apparently abolished by the trypsin treatment. This suggests that cathepsin D is recognized by the lysosomal integral membrane proteins. We demonstrate in the following that cathepsin D is, indeed, bound to the lysosomal membranes.

\section{DISCUSSION}

Several observations have suggested that the precursor form of lysosomal cathepsin D associates with the intracellular membranes which complement the MPRdependent sorting mechanisms, ${ }^{4,5}$ since this membraneassociation is independent of the presence of $N$. glycosylation. Also, procathepsins D and $L$ were found 
to be associated with the microsomal membranes during biosynthesis as revealed by in vitro binding experiments. ${ }^{6-8)}$ This suggested that the polypeptide backbone of cathepsin D is recognized by the intracellular microsomal membranes. However, the interaction between cathepsin D and the isolated lysosomal membranes has not yet been clarified. If part of the precursor cathepsin $\mathrm{D}$ is translocated to the lysosomes by this proposed MPR-independent sorting mechanism, intracellular membranes such as the endosomes or lysosomes should have an appreciable capacity to bind the cathepsin D polypeptide.

In this paper, to determine whether the cathepsin D molecule binds to the lysosomal membranes, in vitro binding experiments were carried out employing the lysosomal cathepsin $\mathrm{D}$ fraction or the microsomal procathepsin D fraction. Rat liver lysosomal membranes were prepared by osmotic shock and $1 \mathrm{M} \mathrm{NaCl}$ washing procedure and were analyzed by SDS-PAGE and immunoblotting. Immunoblotting analysis revealed that the intermediate form of cathepsin D is bound to the lysosomal membranes, and that this lysosomal membraneassociated cathepsin $\mathrm{D}$ is effectively released from the membranes by washing with $\mathrm{Na}_{2} \mathrm{CO}_{3}$ (pH 10.6) (Fig. 1), but not with solutions containing M6-P; this suggested that the membrane-bound cathepsin D associates with the lysosomal membranes by ionic-interaction. These results indicate that the lysosomal membrane-associated cathepsin D resides as a peripheral membrane protein in the lysosomal membrane fraction. Immunoblotting analysis demonstrated that the molecular form of cathepsin $\mathrm{D}$ in the extract of lysosomal membranes by $\mathrm{Na}_{2} \mathrm{CO}_{3}$ is the processed intermediate form (Fig. 1). The distribution of cathepsin D activity in this isolated lysosomal fraction was investigated by preparation of the tritosomal fraction; this was further subfractionated into the membrane fraction and the tritosomal content fraction by osmotic shock treatment, and the distribution of cathepsin D enzymic activity was measured. The level of membrane-associated cathepsin D appeared to be significantly low as compared to those of the enzymatically active and soluble form of mature enzyme (Table 1). It is not clear at present whether the processed intermediate form of cathepsin $D$ is enzymatically active. However, it is assumed that in the lysosomal fraction most of the cathepsin D exists as the completely processed mature form which is enzymatically active; therefore, the membrane-bound intermediate form is presumably an inactive enzyme. During its transport

Table 1. Distribution and Recovery of Cathepsin D in Subtritosomal Fractions

\begin{tabular}{ccccc}
\hline \hline & \multicolumn{4}{c}{ Subtritosomal fractions } \\
\cline { 2 - 5 } Enzyme & Tritosomes & Contents & $\begin{array}{r}1 \mathrm{M} \mathrm{NaCl} \\
\text { washings }\end{array}$ & Membranes \\
\hline Cathepsin D & & & & 48 \\
$\quad \begin{array}{c}\text { Specific activity } \\
\text { Yield (\%) }\end{array}$ & 224 & 292 & 140 & 4.5 \\
$\begin{array}{c}\text { Protein } \\
\text { Yield (\%) }\end{array}$ & 100 & 91.0 & 5.5 & 20.8 \\
\hline
\end{tabular}

The specific activity of cathepsin D is defined as units/mg protein. along the intracellular sorting pathway, the membraneassociated precursor cathepsin D changes to the soluble mature form and then is released into the lysosomal content fraction as it goes through the proteolytic processing steps in endosomes or lysosomes. When the prepared lysosomal membranes were subjected to the osmotic shock treatment followed by the washing procedure with $1 \mathrm{M} \mathrm{NaCl}$ and digested with trypsin, we found that the membrane-associated cathepsin $\mathrm{D}$ was sensitive to the externally added trypsin, and that the cathepsin D polypeptide band completely disappeared after digestion. Thus the lysosomal membranes were revealed as inverted vesicles by the osmotic shock treatment (Fig. 2). The same result was obtained when tritosomal membranes were used. If cathepsin $\mathrm{D}$ has a binding affinity to the lysosomal integral membranous proteins, these membranous proteins could be exposed outside of the inverted lysosomal membranes. To examine the interaction between cathepsin D and the lysosomal membranous proteins, inverted lysosomal membranes were prepared by osmotic shock treatment and were stripped of cathepsin $\mathrm{D}$ by $\mathrm{Na}_{2} \mathrm{CO}_{3}$ ( $\mathrm{pH}$ 10.6) containing $10 \mathrm{~mm}$ M6-P, then used in the in vitro binding experiments. The results suggested that cathepsin D derived from the lysosomal membrane fraction rebinds to the inverted lysosomal membranes at $\mathrm{pH} 4.5$ as well as 7.4 (Fig. 3), however, the soluble form of mature enzyme did not bind to the lysosomal membranes (data not shown). This rebinding was not mediated by M6-P or nonspecific interaction since the binding buffer included $10 \mathrm{~mm}$ M6-P. The interaction of lysosomal membranes with the microsomal procathepsin D was also investigated, and found evidence that procathepsin D rebinds efficiently to the lysosomal membranes at acidic $\mathrm{pH}$ of 4.5 but not at neutral $\mathrm{pH}$ of 7.4 (Fig. 4). It remains to be elucidated whether $\mathrm{N}$-terminal propeptide region of cathepsin $\mathrm{D}$ indeed interacts with the lysosomal membranes. The microsomal procathepsin $\mathrm{D}$ did not show a binding affinity to the lysosomal membranes at pH 7.4 (Fig. 4), while, the intermediate form apparently did bind to the membranes at this neutral $\mathrm{pH}$ (Fig. 3). The reason for the difference in the binding affinity thus observed cannot be explained at present. It was reported that procathepsin D preferentially binds to the microsomal membranes at $\mathrm{pH}$ 5.0 but not at $\mathrm{pH} 6-8^{7,8)}$; the results presented here seem to be in good accord with those findings.

To confirm that the intermediate form of cathepsin D specifically interacts with the lysosomal integral membrane proteins, the lysosomal membrane fraction was treated with serine proteinase, trypsin, and binding experiments were carried out. The binding capacity of cathepsin D to the lysosomal membranes was apparently abolished by the trypsin treatment at $\mathrm{pH} 7.4$, and the decreased binding of cathepsin $\mathrm{D}$ to the membranes was observed at $\mathrm{pH} 4.5$ (Fig. 5). These results imply that the intermediate form cathepsin D is specifically recognized by the lysosomal membranous proteins. A similar observation was reported previously: trypsin treatment on microsomal membranes caused to reduction in the acid $\mathrm{pH}$-dependent binding of procathepsin L, although the treatment did not totally abolish the membrane binding of procathepsin $\mathrm{L}$ to the 


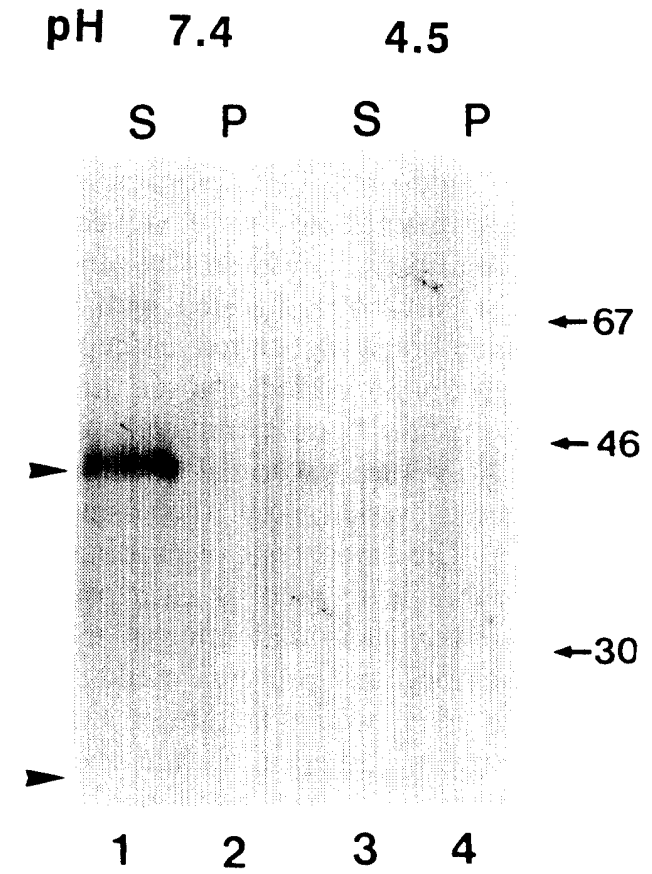

Fig. 5. The Binding Capacity of Cathepsin D to the Lysosomal Membranes is Reduced by Trypsin Treatment

The lysosomal membrane fraction washed with $1 \mathrm{M} \mathrm{NaCl}$ was incubated with trypsin $(100 \mu \mathrm{g} / \mathrm{ml})$ for $60 \mathrm{~min}$. Proteolysis was inhibited by addition of the trypsin inhibitor $(500 \mu \mathrm{g} / \mathrm{ml})$ and the mixture was then centrifuged at $105000 \times \mathrm{g}$ for $60 \mathrm{~min}$ at $4{ }^{\circ} \mathrm{C}$. The lysosomal membranes thus obtained were incubated with the lysosomal membrane-wash fraction containing the intermediate form of cathespin $\mathrm{D}$ at $\mathrm{pH}$ 4.5 (lanes 3,4) or 7.4 (lanes 1,2 ); the membrane (lanes 2,4) and the soluble fractions (lanes 1,3 ) were then separated by centrifugation at $105000 \times g$ for $60 \mathrm{~min}$ at $4{ }^{\circ} \mathrm{C}$, followed by analysis by SDS-PAGE and immunoblotting with specific IgG. The upper arrowhead at the left indicates the intermediate form of cathepsin $\mathrm{D}$, while the lower arrowhead indicates the position of partially degraded product of the intermediate form of cathepsin D during incubation. Numbers to the right indicate the masses of molecular weight standards in kilodaltons.

membranes. ${ }^{7)}$ We have recently succeeded in expressing rat cathepsin D cDNA in Saccharomyces cerevisiae in which the precursor enzyme was correctly transported to the yeast vacuoles, as shown by cell fractionation experiments and morphological analysis. ${ }^{13)}$ Mutational analysis further demonstrated that the propeptide-deleted cathepsin D is not efficiently transported to the yeast vacuoles, but that it is localized in the small vesicles in the cytoplasm, suggesting that the polypeptide portion of cathepsin D recognizes the vacuolar sorting mechanism. Further investigation will be needed to clarify the detailed targeting mechanism for lysosomal cathepsin in our expression system in yeast cells.

It is assumed that the components of membranous proteins in the lysosomal membranes are apparently different from those in the microsomal fraction, ${ }^{16)}$ but it is interesting to note that the early biosynthetic form of cathepsins $\mathrm{D}$ and $\mathrm{L}$ has a preferential binding affinity to the membrane proteins of lysosomes or microsomes. ${ }^{6-8)}$ If the membranous proteins recognized by the precursor cathepsin D have an important role to deliver cathepsins to the lysosomes, we assume that similar membranous proteins are localized in both the lysosomal and microsomal fractions. Identification of such membranous proteins which complement the MPR-dependent targeting mechanisms will further clarify this unidentified lysosomal protein sorting mechanism on the intracellular sorting pathway.

\section{REFERENCES}

1) Kornfeld S., Mellman I., Ann. Rev. Cell Biol., 5, 483 (1989).

2) Barrett A. J., "Proteinases in Mammalian Cells and Tissues," ed. by Barrett A. J., North-Holland Publishing Company, Amsterdam, 1977, pp. 209-248.

3) Nishimura Y., Kato K., Furuno K., Himeno M., Biol. Pharm. Bull., 18, 825 (1995).

4) Rijnboutt S., Aerts H. M. F. G., Geuze H. J., Tager J. M., Strous G. J., J. Biol. Chem., 266, 4862 (1991).

5) Rijnboutt S., Kal A. J., Geuze H. J., Aerts H., Strous G. J., J. Biol. Chem., 266, 23586 (1991).

6) Diment S., Leech M. S., Stahl P. D., J. Biol. Chem., 263, 6901 (1988).

7) McIntyre G. F., Erickson A. H., J. Biol. Chem., 266, 15438 (1991).

8) McIntyre G. F., Godbold G. D., Erickson A. H., J. Biol.Chem., 269, 567 (1994).

9) Johnson L. M., Bankaitis V. A., Emr S. D., Cell, 48, 875 (1987).

10) Valls L. A., Hunter C. P., Rothman J. H., Stevens T. H., Cell, 48, 887 (1987).

11) Valls L. A., Winther J. R., Stevens T. H., J. Cell Biol., 111, 361 (1990).

12) Nishimura Y., Kato K., Arch. Biochem. Biophys., 298, 318 (1992).

13) Nishimura Y., Takeshima H., Sakaguchi M., Mihara K., Omura T., Kato K., Himeno M., J. Biochem. (Tokyo), 118, 168 (1995).

14) Nishimura Y., Kawabata T., Kato K., Arch. Biochem. Biophys., 261, 64 (1988).

15) Nishimura Y., Higaki M., Kato K., Biochem. Biophys. Res. Commun., 148, 335 (1987).

16) Ohsumi Y., Ishikawa T., Kato K., J. Biochem. (Tokyo), 93, 547 (1983).

17) Trouet A. Arch. Intern. Physiol. Biochim., 72, 698 (1964).

18) Leighton F., Poole B., Beaufay H., Baudhuin P., Coffey, J. W., Fowler S., de Duve C., J. Cell Biol., 37, 482 (1968).

19) Anson M. L., J. Gen. Physiol., 22, 79 (1939).

20) Shibko S., Tappel A. L., Biochem. J., 95, 731 (1965).

21) Lowry O. H., Rosebrough N. J., Farr A. L., Randall R. J., J. Biol.Chem., 193, 265 (1951). 